\title{
Molecular Diversity of the Human Immunodeficiency Virus Type 1 in Metropolitan Cities in Central Africa: An Update of Data
}

\author{
Ben Ilunga Bulanda', Berry Ikolango Bongenya', Adawaye Chatte ${ }^{2}$, Elvis Tshunza Kateba ${ }^{1}$, \\ Jean-Yves Debels Kabasele', Médard Okonda Omakoy'1, Divine Chuga1, \\ Christian Tshibumbu1, Idriss Mwanaut ${ }^{1}$, Erick Ntambwe Kamangu 1,3* \\ ${ }^{1}$ Research Group “Focus HIV/AIDS”, Kinshasa, Democratic Republic of Congo \\ ${ }^{2}$ University Institute of Sciences and Technologies of Abéché, Abéché, Chad \\ ${ }^{3}$ Service of Molecular Biochemistry, Department of Basic Sciences, Faculty of Medicine, University of Kinshasa, Kinshasa, \\ Democratic Republic of Congo \\ Email: *erick.kamangu@unikin.ac.cd
}

How to cite this paper: Bulanda, B.I., Bongenya, B.I., Chatte, A., Kateba, E.T., Kabasele, J.-Y.D., Omakoy, M.O., Chuga, D., Tshibumbu, C., Mwanaut, I. and Kamangu, E.N. (2020) Molecular Diversity of the Human Immunodeficiency Virus Type 1 in Metropolitan Cities in Central Africa: An Update of Data. World Journal of AIDS, 10, 80-93.

https://doi.org/10.4236/wja.2020.102007

Received: February 17, 2020

Accepted: May 8, 2020

Published: May 11, 2020

Copyright $\odot 2020$ by author(s) and Scientific Research Publishing Inc. This work is licensed under the Creative Commons Attribution International License (CC BY 4.0).

http://creativecommons.org/licenses/by/4.0/ (c) $\underset{\mathrm{By}}{\mathrm{By}}$ Open Access

\begin{abstract}
The Human Immunodeficiency Virus (HIV) has a diversity that is equal to the complexity of its management. The group $\mathrm{M}$ (Major) is the dominant group in Sub-Saharan Africa and its distribution is very heterogeneous; the diversity of the virus is more heterogeneous in this region than elsewhere in the world which follows a complex and specific algorithm because of geographical positions and countries. This distribution is very dynamic, evolving and unpredictable. This review aimed to expose the specifics of the HIV Type 1 epidemic in Central Africa, in terms of the different molecular variants of HIV published for the region compared to the geographic location. Both Type 1 and Type 2 of HIV are prevalent in sub-Saharan Africa due to distinct geographical contexts. HIV-2 is mainly documented in West and Central Africa, particularly in Cameroon, Guinea-Bissau, Gambia, Senegal, Ivory Coast and Burkina-Faso however HIV-1 infection is widely distributed across the continent. The HIV-1 epidemic in Sub-Saharan Africa is dominated by the Group M. The different subtypes respect a certain geographical distribution across the continent. West Africa is dominated by subtype A, East and South Africa are dominated by subtype $\mathrm{C}$, while Central Africa is dominated by strains A, C, D, F, H, J, CRF01-AE and CRF02-AG. This review is the first to present de molecular diversity of HIV-1 in metropolitan cities in all central African countries. The Circulating Recombinant Form (CRF02_AG) and subtypes $A$ and $G$ are present in all Central African countries and are also the
\end{abstract}


most commonly encountered; followed by the subtypes D, F, G, C, B, J, K and several Circulating Recombinant Forms that are not represented in all Central African countries.

\section{Keywords}

Molecular Diversity, HIV, Sub-Saharan Countries, Metropolitan Cities

\section{Introduction}

The Human Immunodeficiency Virus (HIV) has a diversity that is equal to the complexity of its management [1]. The classification of recombinant types, groups, sub-types, sub-sub-types and Recombinant Forms (CRFs-Circulating Recombinant Forms and URFs-Unkown Recombinant Forms) or mutant forms has led to a better understanding of the virus, the distribution and evolution of the epidemic [2] [3]. It has also helped to better guide the care of patients infected with HIV [4]. The group M (Major) is the dominant group in Sub-Saharan Africa and its distribution is very heterogeneous; the diversity of the virus is more heterogeneous in this region than elsewhere in the world [2] (Figure 1). It follows a complex and specific algorithm because of geographical positions and countries [1] [3] [5] [6]. This distribution is very dynamic, evolving and unpredictable.

According to the 2018 reports of the World Health Organization (WHO) and the Joint United Nations Program on HIV/AIDS (UNAIDS), nearly 40 million people live with HIV/AIDS worldwide, of whom almost 27 million South of the

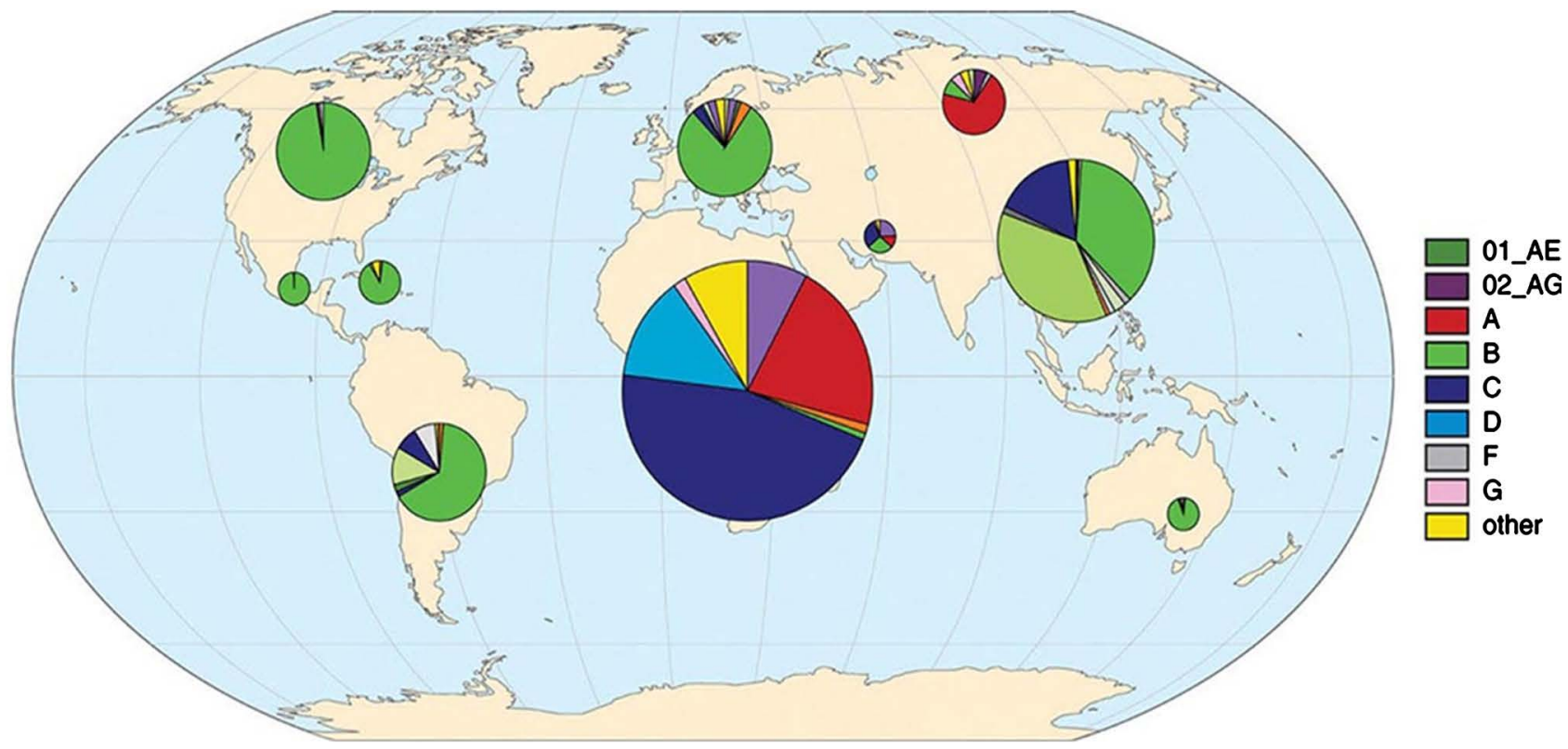

Figure 1. Global geographic distribution of HIV-1 group M subtypes and recombinant forms for 2013. Distributions derived from relative frequency of subtypes among $>500,000$ HIV genomic sequences in the Los Alamos National Laboratory HIV Sequence Database (Additional information available at http://www.hiv.lanl.gov/components/sequence/HIV/geo/geo.comp). 
Sahara, where four out of every five infected adolescents aged between 15 and 19 years are girls [7]. Sub-Saharan Africa has been carrying the heaviest burden of the HIV epidemic for a long time; nearly $70 \%$ of the global epidemic is concentrated there [7] [8]. For the year 2018, about 6200 young women aged from 15 to 24 years were infected with HIV each week south of the Sahara [6] [7]. Central Africa is a region where the prevalence that is more or less stable and low for HIV-1 infection compared to other regions south of the Sahara; in 2015, the average prevalence was $2.6 \%$ for women and $1.8 \%$ for men [9] [10] [11] [12]. This region includes the following countries: Angola, Cameroon, Central African Republic (CAR), Chad, Democratic Republic of Congo (DRC), Equatorial Guinea, Gabon, Republic of Congo (RC), and Sao Tome and Principe (Figure 2).

The purpose of this literature review was to expose the specifics of the HIV Type 1 epidemic in Central Africa, in terms of the different molecular variants of HIV published for the region compared to the geographic location.

\section{Classification of HIV Isolates}

Phylogenetic analyzes of different strains of HIV isolated in different geographical areas have demonstrated the differences that exist within this virus. The different databases available made it possible to differentiate HIV type 1 and 2 as well as their respective groups and subtypes [1] [2] [3]. Each of the types is thus divided into groups which are further subdivided into sub-types, Circulating Recombinant Forms (CRFs) and Unrecognized Forms (URF-Unknown Recombinant Forms).

HIV-1 is divided into 4 groups: M (Major), O (Outlier), N (Non-major and non-outlier) and P [1] [2]. Group $\mathrm{M}$ is responsible for over $3 / 4$ of the global epidemic of HIV/AIDS [2]. The major group (M), which is the majority, is subdivided into distinct sub-types called "pure" (A, B, C, D, F, G, H, J and K) and 48 Recombinant Circular Forms (CRFs). There are currently 98 recombinant subtypes (CRF and URFs) resulting from recombination phenomena between 2 or
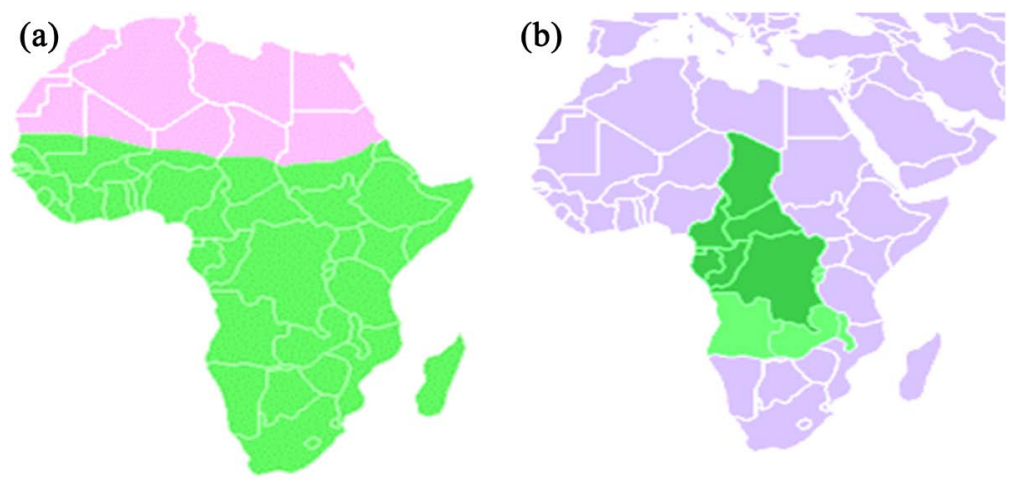

Figure 2. (a) Sub-Saharan African Countries. Over 70\% of the HIV Type 1 epidemic in the world is concentrated in this region. (b) The Central African region includes the following countries: Angola, Cameroon, Central African Republic (CAR), Chad, Democratic Republic of Congo (DRC), Equatorial Guinea, Gabon, Republic of Congo (RC), and Sao Tome and Principe (Source: http://fr.wikipedia.org/wiki/Afrique). 
more different subtype viruses co-infecting the same individual [1]. The viral subtype $\mathrm{B}$ is the dominant subtype found in Europe, the Americas, Asia and Australia [3]. Subtype $\mathrm{C}$ is predominantly responsible for the global HIV/AIDS epidemic [13]. The other groups of HIV-1 (N, O, P), which represent only a minority of circulating strains, are more common in Cameroon and its neighboring countries in Central Africa [1] [2] [3].

HIV-2 is divided into 8 groups named $A$ to $\mathrm{H}$, with groups $\mathrm{A}$ and $\mathrm{B}$ being the most represented [14]. HIV-2 infection is much rarer and is confined mainly to West Africa [13] [15]. In addition, the progression of the disease is much slower than for HIV-1 and this virus is transmitted with difficulty [16]. In general, because of its lower infectivity and slow progression, viral load in individuals infected with HIV-2 is significantly lower than in those infected with HIV-1 [14] [15] [16] [17]. In addition, the arrangement of coding regions on the genome is not identical for both types of virus (Figure 3 ).

\section{HIV Diversity in Sub-Saharan Africa}

Both Type 1 and Type 2 of HIV are prevalent in sub-Saharan Africa due to distinct geographical contexts. HIV-2 is mainly documented in West and Central Africa, particularly in Cameroon, Guinea-Bissau, Gambia, Senegal, Ivory Coast and Burkina-Faso however HIV-1 infection is widely distributed across the continent [13] [15]. Group O infection of HIV-1 is particularly described in Cameroon, Chad, Gabon, Equatorial Guinea and Gabon, but also sporadically in other West African countries in the case of Niger, Nigeria, Senegal and Togo [18]. Infection with the $\mathrm{N}$ and $\mathrm{P}$ group has been documented to date in some Cameroonian patients [19] [20] [21].

The HIV epidemic in Sub-Saharan Africa is dominated by Group M of the Type 1 in general [22]. The different subtypes respect a certain geographical distribution across the continent, particularly in several regions of sub-Saharan Africa: West Africa is dominated by subtype A, East and South Africa are dominated by subtype $C$, while Central Africa is dominated by strains $A, C, D, F, H, J$, CRF01-AE and CRF02-AG [6] [23].

\section{HIV Diversity in Central Africa}

A literature search as conducted to identify the different strains of HIV Type 1 in

HIV-1

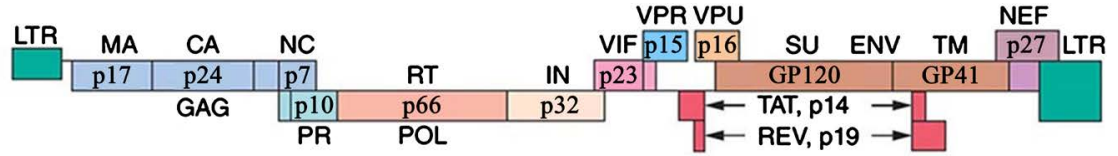

HIV-2

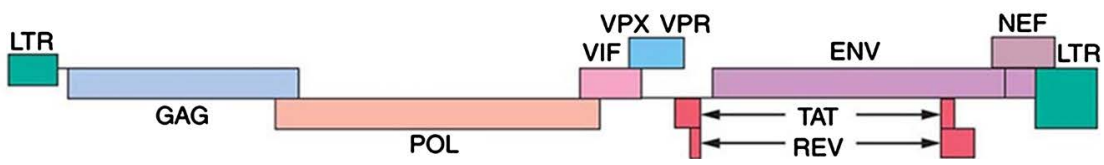

Figure 3. HIV-1 and HIV-2 different coding regions (Source:

https://jvi.asm.org/content/92/14/e00554-18). 
central African metropolitan cities. It was carried using different research sites (MEDLINE/PubMed, public accessible articles, Cochrane Library, and Google scholar) using specific keywords. Limited to the last 15 years, literatures were selected according to the relevance of the results, the representativeness of the samples, the measurement of the methods and the objectives.

Although the HIV epidemic in this region is also dominated by HIV-1 group $\mathrm{M}$, the other groups (N, O and $\mathrm{P}$ ) are also found there and even HIV-2 [5] [6]. The percentage of new HIV-1 infections in this region has remained largely below $10 \%$ for the majority of countries [5] [10] [12]. Here is the situation of the prevalence HIV in the Central African countries for 2017 in the population aged from 15 to 49 years: 7\% for Cameroon, 4.2\% for Gabon, 2\% for Equatorial Guinea, $2 \%$ for the Central African Republic (CAR), $4 \%$ for the Democratic Republic of Congo (DRC), $2 \%$ for the Republic of Congo (RC) and $2 \%$ for Chad (Figure 4) [8]. The prevalence of HIV-1 in the population aged from 20 to 29 years in 2018 exceeded 3\% in 3 Central African countries, namely Cameroon (7\%), Gabon (6.7\%) and the Republic of Congo (5.2\%); it was 3\% for Chad, 2.7\% for Equatorial Guinea, $1.3 \%$ for the DRC, and $1.2 \%$ for Sao Tome and Principe (Figure 4) [9].

In 2010 in Luanda, Angola, as part of the Mother-to-Child Transmission of HIV/AIDS (PMTCT) prevention program, a study was conducted on 57 HIV-1 infected and naively treated pregnant women (Table 1) [24]. Of 57 samples taken, 35 had been sequenced successfully after phylogenetic analysis of the pol region; the following sub-types and Circulating Recombinant Forms were identified: F (22.8\%), C (17.1\%), A (14.2\%), D (8.5\%), CRF02_AG (8.5\%), G (8.5\%), U (7.2\%), H (5.7\%), CRF13_cpx (3.6\%) and CRF37_cpx (3.6\%) (Figure 5 \& Figure 6). Another study has been carried out at the Lucrecia Paim Maternity Clinic always in Luanda (Table 1), from April to June 2018 on 42 plasma samples of HIV-positive pregnant women [25]. Here are the sub-types and Circulating Recombinant Forms that had been identified from the 34 sequenced samples: $\mathrm{C}$ (38\%), F (18\%), A (9\%), G (9\%), D (6\%), CRF02_AG (6\%), CRF37_cpx (3\%), F1/C (3\%), A1/G (3\%), H/G (3\%) and H (3\%) (Figure 5 \& Figure 6).

In 2016 in Yaoundé, Cameroon, Colleen R, et al. conducted a study of 90 samples taken from 2011 to 2013 in 90 treatment-naive subjects using a phylogenetic analysis of the gag and pol regions (Table 1) [26]. They identified the following sub-types: CRF02_AG (64.9\%), CRF22_01A1 (7.1\%), D (4.5\%), F (3.9\%), G (3.2\%), CRF18_cpx (3.2\%), CRF37_cpx (3.2\%), CRF11_cpx (2.6\%), CRF13_cpx (1.9\%), A (1.9\%), CRF01_AE (1.3\%), CRF09_cpx (1.3\%) and H $(0.6 \%)$. These sequence data for the gag and pol regions were obtained from 62 subjects. A similar study has revealed: CRF02_AG (68.6\%), G (8.2\%), F (6.7\%), A (4.6\%) and D (3.8\%) (Figure 5 \& Figure 6) [27]. Another study published in 2017 by Georges T et al. (Table 1), still carried out in Yaoundé between 2008 and 2015 on $141 \mathrm{HIV}-1$ patients, had allowed after phylogenetic analysis of the same regions (gag and pol), the identification of subtypes and Circulating Re- 
combinant Forms: CRF02_AG (67.37\%), URFs (7\%), CRF11_cpx (5.67\%), G (4.2\%), CRF22_01A1 (2.1\%), CRF01_AE (2.1\%), CRF18_cpx (2.1\%), CRF13_cpx (2.1\%), F (2.1\%), D (2.1\%), A (1.4\%) and CRF37_cpx (1.4\%) (Figure 5 \& Figure 6) [28]. The group $M$ remains the most prevalent in Cameroon, a country known as the epicenter of HIV-1 in Central Africa with a diversity of groups (M, $\mathrm{N}, \mathrm{O}$ and $\mathrm{P}$ ), subtypes and circulating Recombinant forms that did not nothing of equal; this is for example the case of CRF22_01A1, another twenty-second recombinant described after the CRF22_cpx and which indicates a combination between the CRF01_AE and the sub-sub-type A1 [29]-[35].

In 2012 in Gabon, Florian L, et al. published a study conducted between 2010 and 2011 in two Centers for the Care of the People Living with HIV/AIDS (PLHIV), located in two cities, namely Franceville and Koulamoutou, on a cohort of 375 adult patients on Anti-Retroviral Therapy (ART) for at least 12 months (Table 1) [36]. Of the 375 samples that were collected, only 141 were sequenced and identified the following subtypes and Circulating Recombinant Forms: CRF02_AG (32.6\%), A (16.3\%), G (7.8\%), CRF37_cpx (6.3\%), D (4.9\%), CRF01_AE (3.5\%), CRF25_cpx (3.5\%), C (2.1\%), H (2.1\%), CRF11_cpx (2.1\%), F2 (0.7\%), J (0.7\%) ), CRF06_cpx (0.7\%), CRF09_cpx (0.7\%), CRF36_cpx (0.7\%) and CRF43_02G (0.7\%); in addition, Unique Recombinant Forms (URFs) accounted for $14 \%$. It should be noted that CRF43_02G is a Circulating Recombinant Form from a combination of CRF02_cpx and subtype G (Figure 5 \& Figure 6) [37].

In 2010, a study was conducted in the city of Malabo in Equatorial Guinea on a cohort of 41 HIV-1 patients (Table 1) [38]. CRF02_AG accounted for $53.7 \%$ of the strains and 11 different variants were obtained in the remaining 19 samples: subtype G (7.3\%), A (7.2\%), C (4.8\%), CRF26_AU (4.8\%), F (4.8\%), CRF06_cpx (2.4\%), CRF09_cpx (2.4\%), CRF11_cpx (2.4\%) and CRF22_cpx (2.4\%) (Figure 5 \& Figure 6). Another study published in 2016 by Patricia A et al. (Table 1), carried out as part of the PMTCT program on 69 pregnant women infected with HIV-1 selected between November 2012 and December 2013 in the cities of Malabo and Bata, had allowed the identification Subtypes and Circulating Recombinant Forms: CRF02_AG (55.2\%), CRF22_A101 (10.5\%), C (10.5\%), U (5.3\%), A (2.6\%), F (2.6\%), B (2.6\%) ), D (2.6\%), G (2.6\%), CRF06_cpx (2.6\%) and CRF11_cpx (2.6\%) (Figure 5 \& Figure 6) [39].

In 2006, for the city of Bangui in the Central African Republic (CAR) (Table 1), a study in 117 adult HIV-1 infected patients showed that the recombinant form CRF11_cpx was the most common (38.4\%) and 14 other subtypes and other recombinant forms for the $M$ group: A (18.8\%), G (11.1\%), CRF01_AE (5.9\%), B (2.5\%), CRF02_AG (2.5\%), F2 (1.7\%), CRF09_cpx (1.7\%), D (0.8\%), C $(0.8 \%), \mathrm{H}(0.8 \%), \mathrm{J}(0.8 \%), \mathrm{CRF} 06 \_\mathrm{cpx}(0.8 \%), \mathrm{CRF} 13 \_\mathrm{cpx}(0.8 \%)$ and CRF19_cpx (0.8\%) (Figure 5 \& Figure 6) [40]. In another study conducted by Hélène P and al. in 2012 on 386 PVV still in Bangui (Table 1), the following subtypes and circulating recombinant forms were identified: CRF11_cpx (35\%), U (15\%), A (12\%), CRF01_AE (12\%), G (12\%), D (5\%), H (3\%), CRF02_AG 
(3\%) and CRF13_cpx (3\%) (Figure 5 \& Figure 6) [41].

In 2015, for Kinshasa in the Democratic Republic of Congo (DRC), subtype A was predominant with $22.9 \%$ followed by subtypes CRF02_AG (11.1\%), C (9.8\%), G (9.8\%), K (9.8\%), D (7.8\%), H (7.8\%), J (5.9\%), U (5.2\%), F (3.9\%), CRF01_AE (3.3\%) and B (2\%) [42]. Phylogenetic analyzes were performed on the regions of Viral Protease and Reverse Transcriptase (RT) (Figure 5 \& Figure 6) [42]. Subtype A has dominated the HIV-1 epidemic in Kinshasa since the declaration of HIV infection in the DRC [43]. This plurality of strains was also documented in previous years. However, the high prevalence of CRF02_AG in 2015 brings a change in later data on the distribution of HIV-1 strains in the city [42]. Recent studies carried out on the population of Professionals Sex Workers (PSW) in Kinshasa (Table 1), presented tables of different subtypes compared to the general population; which shows that these key populations do not always reflect the general population. In PS, subtype $\mathrm{K}(25 \%)$ was dominant, followed by subtypes A (15\%), G (15\%), C (10\%), J (10\%), U (10\%), CRF02_AG (10\%) and $\mathrm{H}$ (5\%) (Figure 5 \& Figure 6) [44]. Another study, published in 2016, reported the presence of HIV Type 2 in Kinshasa in a population of Type 1 HIVinfected and antiretroviral-treatment-naive (ART) patients [45]. The HIV-1/ HIV-2 coinfection rate was $3.54 \%$ in this population [45]. This data puts into question the distribution of HIV-2 in the global epidemic.

In 2015, a study was conducted in Pointe Noire, Republic of Congo, to prevent mother-to-child transmission of HIV-1 and to determine the prevalence of different subtypes and transmitted mutations related to drug resistance (Table 1) [46]. Ninety-five (95) plasma samples were initially collected and 68/95 (71.6\%) samples were sequenced successfully. In particular, 35\% of the sequences were classified as URFs, $11.7 \%$ as the sub-type A, 10.3\% as CRF45_cpx, $8.8 \%$ as the sub-type G, 7.4\% as CRF37_cpx, 5.9\% as CRF18_cpx, 4.4\% as the sub-type D, $2.9 \%$ as the sub-type B, $2.9 \%$ as the sub-type $\mathrm{H}, 2.9 \%$ as CRF02_AG, while the subtypes $\mathrm{C}$ and J, subtypes $\mathrm{F} 1$ and F2, and CRF25_cpx were found only in one sample each (Figure 5 \& Figure 6). Major mutations of NRTIs, NNRTIs and PIs were detected in $8.8 \%$ viral sequences. NNRTIs mutations were found in 3 patients (4.4\%).

In Chad, the type of HIV that has been circulating since the onset of HIV infection is mainly HIV-1 (Table 1) [47]. Among groups circulating throughout the country, only the $M$ group is found to date with mainly 4 sub-types (A, D, F and $\mathrm{G}$ ) which co-circulate with 3 major recombinant forms (CRF01_AE, CRF02_ AG and CRF11_Cpx) (Figure 5 \& Figure 6) [47]. In 2017, in a study published by Adawaye $C$ et al. (Table 1), conducted between 2011 and 2012 at N'Djamena National General Referral Hospital in 116 PVV on ARV, the following sub-types were identified after sequencing protease-RT 43: J (30\%), CRF02_AG (30\%), G (16\%), A (9\%), D (9\%) and F (5\%) (Figure 5 \& Figure 6) [48]. A few rare cases of Group O have been presented, but Group $\mathrm{N}$ as well as Type 2 HIV have not yet been seen in Chad [49].

Data on the diversity of HIV-1 group M for Sao Tome and Principe were not 


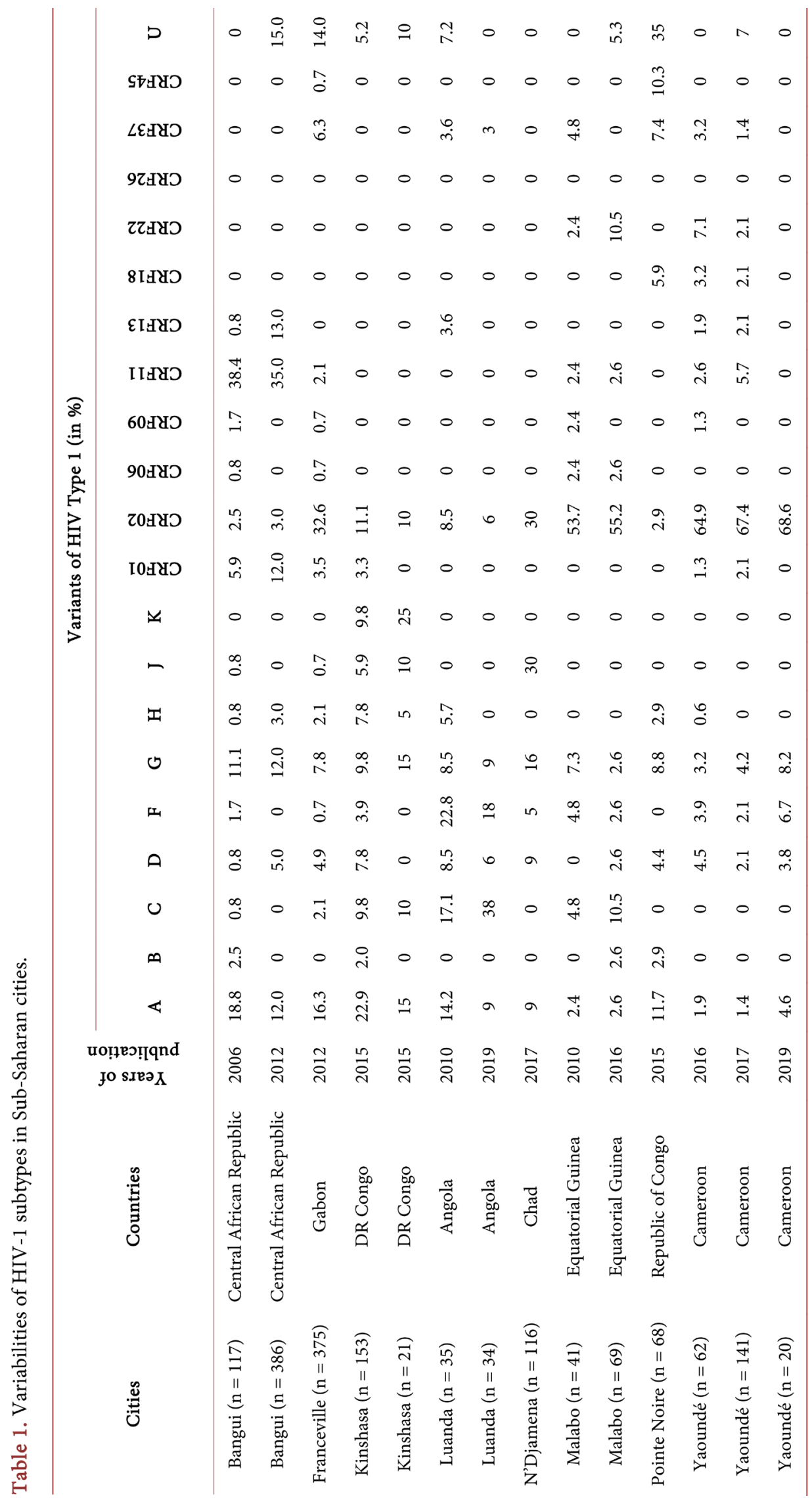




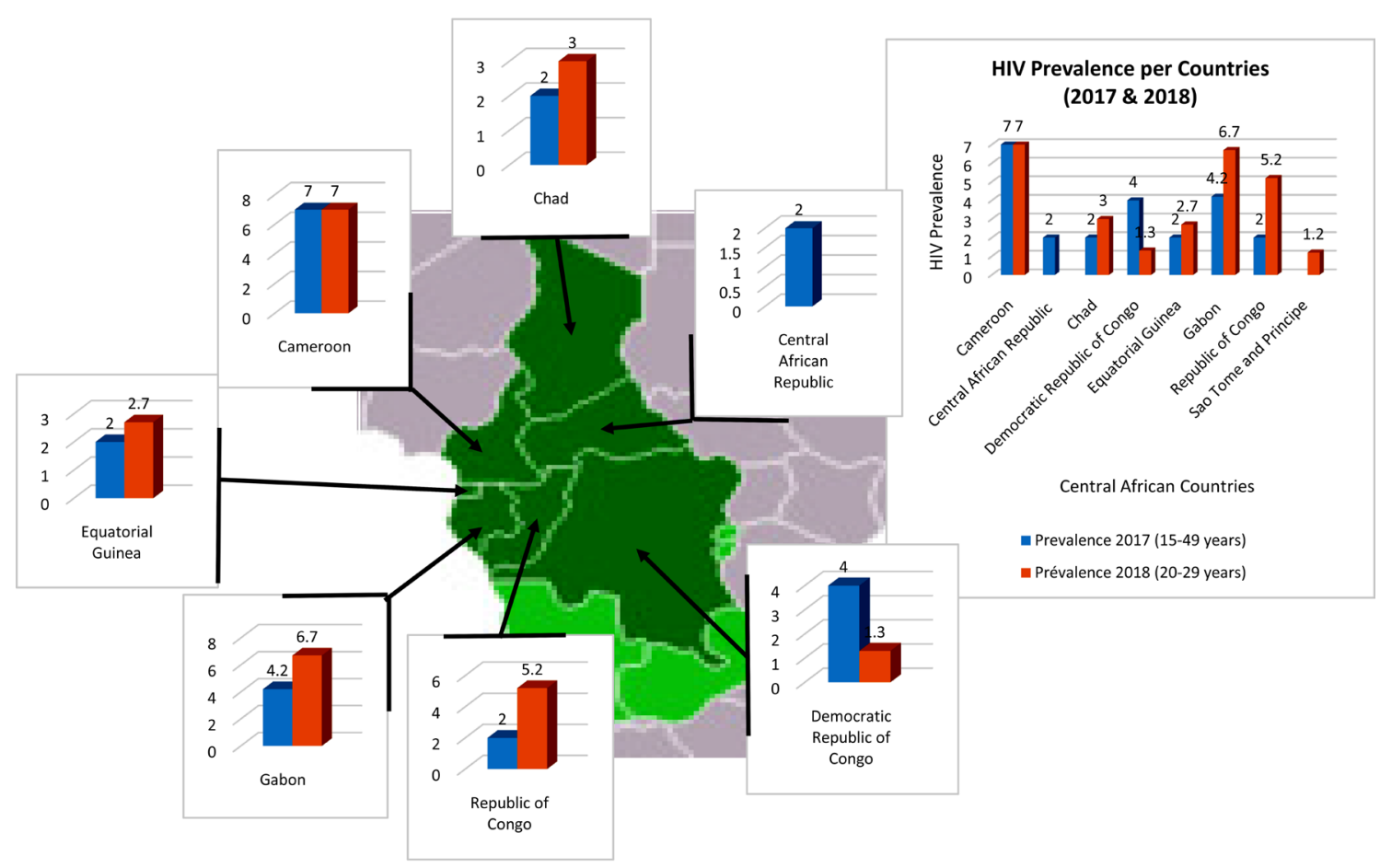

Figure 4. Prevalence of HIV in Central African Countries. HIV prevalence in the Central African countries for 2017 in the population aged from 15 to 49 years: 7\% for Cameroon, $4.2 \%$ for Gabon, 2\% for Equatorial Guinea, 2\% for the Central African Republic (CAR), $4 \%$ for the Democratic Republic of Congo (DRC), $2 \%$ for the Republic of Congo (RC) and $2 \%$ for Chad [Blue]. HIV prevalence in the population aged from 20 to 29 years in 2018: 7\% for Cameroon, 6.7\% for Gabon, 5.2\% for the Republic of Congo, 3\% for Chad, $2.7 \%$ for Equatorial Guinea, $1.3 \%$ for the DRC, and 1.2\% for Sao Tome and Principe [Orange].

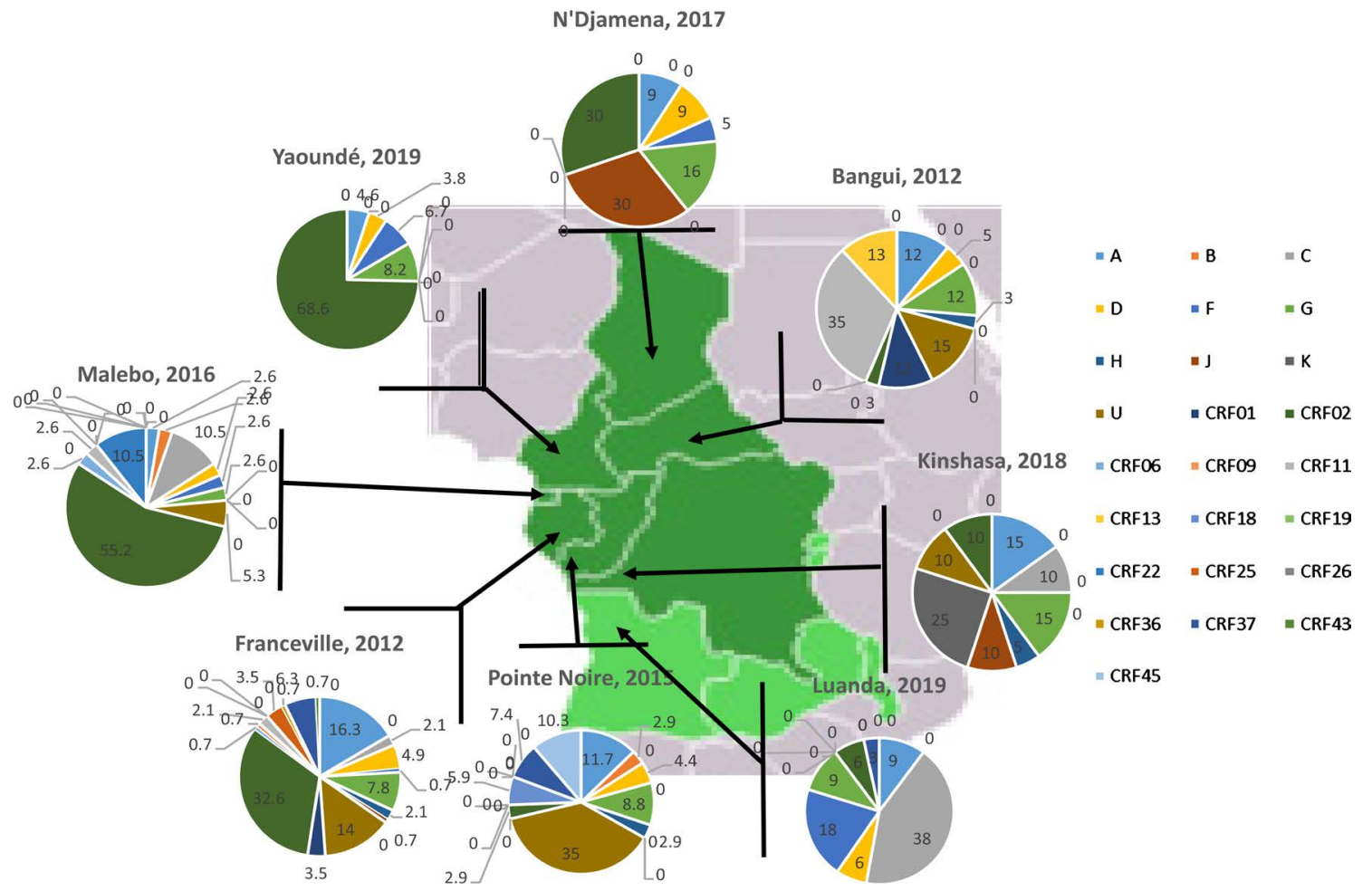

Figure 5. Geographic distribution of HIV-1 in metropolitan cities in Central Africa. The subtypes A, C, D and G, and the CRF_01 and_02 are common in most central African countries. 
Variability of HIV Type 1 subtypes in Metropolitan Cities in Central Africa

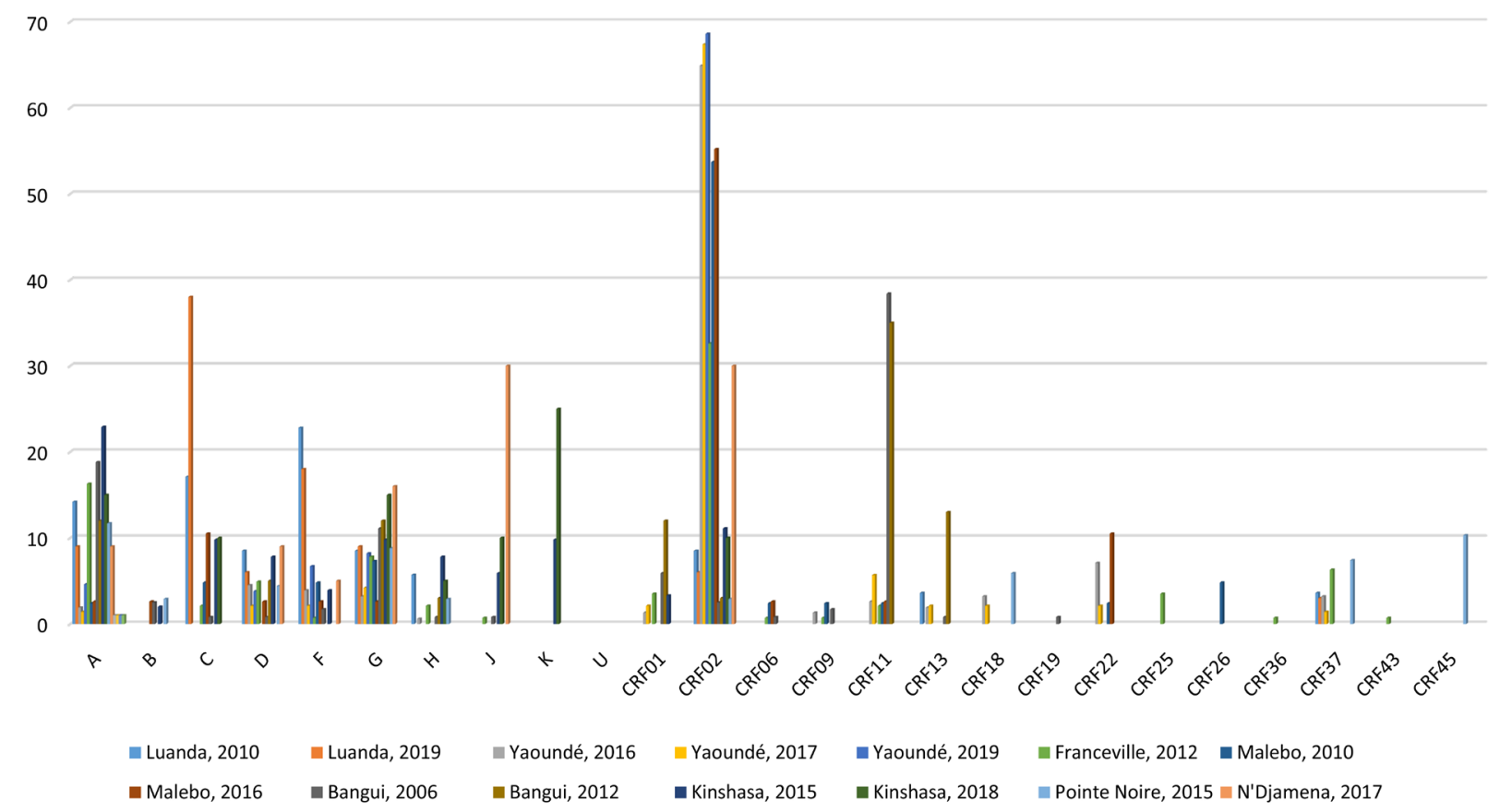

Figure 6. Variability of HIV Type 1 in metropolitan cities in Central Africa.

available. This is the same observation made by Raphael WL and al. in 2012, in her bibliographic review on the genetic diversity of HIV-1 in Africa [49]. This situation may play a growing role in the HIV/AIDS epidemic.

\section{Conclusion}

The increased use of automated sequencing technology has made it possible to monitor the spread of HIV and its prognosis for several countries. Circulating Recombinant Form CRF02_AG and subtypes A and G are present in all Central African countries and are also the most commonly encountered; followed by the D, F, G, C, B, J, K subtypes and several Circulating Recombinant Forms that are not represented in all Central African countries.

\section{Conflicts of Interest}

The authors declare no conflicts of interest regarding the publication of this paper.

\section{References}

[1] Camille, T. (2018) Définition in silico d'épitopes induisant une réponse T cytotoxique en fonction de la variabilité virale du VIH-1 et de l'immunogénétique des patients. Médecine humaine et pathologie. Université de Bordeaux. NNT: 2018BORD0153.

[2] Hemelaar, J. (2016) Implications of HIV Diversity for the HIV-1 Pandemic. The Journal of Infection, 66, 391-400. https://doi.org/10.1016/j.jinf.2012.10.026

[3] Maartens, G., Celum, C. and Lewin, S.R. (2014) HIV Infection: Epidemiology, Patho- 
genesis, Treatment, and Prevention. The Lancet, 384, 258-271. https://doi.org/10.1016/S0140-6736(14)60164-1

[4] Philippe, M. (2016) Prise en charge médicale des personnes vivant avec le VIH (Infection VIH-2 et diversité des VIH-1). Conseil National du Sida et des hépatites virales, 18 .

[5] Kamangu, N.E., Kabututu, Z., Mvumbi, L.G., Kalala, L.R. and Mesia, K.G. (2013) Genetic Diversity of Human Immunodeficiency Virus Type 1 in the Democratic Republic of Congo: A Review of Available Data. International Journal of Collaborative Research on Internal Medicine \& Public Health, 5, 295-309. https://doi.org/10.1136/sextrans-2013-051184.0720

[6] Kamangu, N.E. (2018) Implication of Neighbors in the Genetic Diversity of the Human Immunodeficiency Virus Type 1 in the Democratic Republic of Congo. ARC Journal of AIDS, 3, 26-27.

[7] ONUSIDA (2018) Fiche d'information: Dernière statistiques sur l'état de l'épidémie de sida. Consulted on 08/09/2019 at 10am.

[8] (2018) Fact Sheet on HIV Disease/UNAIDS Data 2018. Consulted on 22/10/2019 at $2 \mathrm{pm}$.

[9] (2019) Fact Sheet on HIV Disease/UNAIDS Data 2019. Consulted on 31/10/2019 at $4 \mathrm{pm}$.

[10] ONUSIDA (2018) Un long chemin reste à parcourir et combler les écarts. http://www.unaids.org/sites/default/files/20180718 PR miles-to-go fr.pdf

[11] Masquelier, B., Eaton, J.W., Gerland, P., Pelletier, F. and Mutai, K.K. (2017) Age Patterns and Sex Ratios of Adult Mortality in Countries with High HIV Prevalence. AIDS, 31, 77-85. https://doi.org/10.1097/QAD.0000000000001332

[12] ONUSIDA (2019) Plan de rattrapage de l'Afrique de l'ouest et du centre accélérer le traitement du VIH d'ici à 2018. Consulted on 09/09/2019 at $6 \mathrm{pm}$.

[13] Marc, C. (2014) Maladies infectieuses et vecteurs: écologie, génétique, évolution et contrôle. Oxford University Clinical Research Unit Hanoï Vietnam, 85, 35-46.

[14] Kannangai, R., Sridharan, G. and David, S. (2012) Human Immunodeficiency Virus Type-2-A Milder, Kinder Virus: An Update. Indian Journal of Medical Microbiology, 30, 6. https://doi.org/10.4103/0255-0857.93014

[15] Freed, E.O, and Martin, M.A. (2013) Human Immunodeficiency Viruses, in Fields Virology. Philadelphia.

[16] Xavier, L., Takeshi. S., Matteo, G., Silvia, C., Cécile, C., Ilse, H., Ahmed, E.M., Christine, L., Jean-Danie, L. and Nicolas, M. (2013) The Capsids of HIV-1 and HIV-2 Determine Immune Detection of the Viral cDNA by the Innate Sensor cGAS in Dendritic Cells. Immunity, 39, 1-11. https://doi.org/10.1016/j.immuni.2013.11.002

[17] Gisselquist, D. (2003) Emergence of the HIV Type 1 Epidemic in the Twentieth Century: Comparing Hypotheses to Evidence. AIDS Research and Human Retroviruses, 19, 8. https://doi.org/10.1089/088922203771881158

[18] Guillemette, U. (2018) Infection par le VIH-1 groupe O: étude des caractéristiques épidémiologiques et de la réponse immuno-virologique aux antirétroviraux. Santé publique et épidémiologie. Université Paris-Saclay. ffNNT: 2018SACLS131f.

[19] Péré, H., Roques, P., Talla, F., Meillo, H., Charpentier, C, and Bélec, L. (2015) Sustained Virological Failure in Cameroonese Patient Infected by HIV-1 Group N Evidenced by Sequence-Based Genotyping Assay. AIDS, 29, 1267-1269. https://doi.org/10.1097/QAD.0000000000000704 
[20] Mourez, T., Simon, F. and Plantier, J.C. (2013) Non-M Variants of Human Immunodeficiency Virus Type 1. Clinical Microbiology Reviews, 26, 448-461. https://doi.org/10.1128/CMR.00012-13

[21] Sante-Publique-France (2017) Point épidémiologique: Découvertes de séropositivité VIH et de SIDA, 104.

[22] Joel, O.W., Andrew, J.L.B., Lance, N.H., Sanjay, R.M., Douglas, D.R., Davey, M.S. and Sergei, L.K. (2014) The Global Transmission Network of HIV-1. J Infect Dis.; 209, 304-313.

[23] Ouerdia, M. (2016) Relations structure-fonction du premier transfert de brin chez le vih-1. Université Paris-Saclay. Français. NNT: 2016SACLN062. Tel-01450381.

[24] Emingarda Patrıcia, A.F.C., Edvaldo da, S.S., Ana Maria, S.C., Angelica, N.M., Luiz Claudio, A.A. and Amilcar, T. (2010) Frequency of Primary Resistance to Antiretroviral Drugs and Genetic Variability of HIV-1 Among Infected Pregnant Women Recently Diagnosed in Luanda-Angola. AIDS Research and Human Retroviruses, 26, 1313-1316. https://doi.org/10.1089/aid.2010.0111

[25] Sebastião, C.S., Neto, Z., de Jesus, C.S., Mirandela, M., Jandondo, D., Couto-Fernandez, J.C., Tanuri, A., Morais, J. and Brito, M. (2019) Genetic Diversity and Drug Resistance of HIV-1 among Infected Pregnant Women Newly Diagnosed in Luanda, Angola. PLoS ONE, 14, e0225251. https://doi.org/10.1371/journal.pone.0225251

[26] Colleen, R.C., Lucy, A., Arlette, F., Stephanie, C., Bladine, A., Josephine, M., Johnson, N., Indira, H. and Philippe, N.N. (2016) Monitoring HIV-1 Group M Subtypes in Yaoundé, Cameroon Reveals Broad Genetic Diversity and a Novel CRF02_AG/F2 Infection. AIDS Research and Human Retroviruses, 32, 4.

https://doi.org/10.1089/aid.2015.0286

[27] Meriki, H.D., Tufon, K.A., Anong, D.N., Atanga, P.N., Anyangwe, I.A., Cho-Ngwa, F. and Nkuo-Akenj, T. (2019) Genetic Diversity and Antiretroviral Resistance Associated Mutation Profile of Treated and Naïve HIV-1 Infected Patients from the Northwest and Southwest Regions of Cameroon. PLOS ONE, 14, e0225575. https://doi.org/10.1371/journal. pone.0225575

[28] Georges, T., Claude, T.T., Dora, M., Julius, Y.F., Joseph, F., Emilienne, N., Léopoldine, K., Alfred, K.N. and Georgette, D.K. (2017) Gag P2/NC and POL Genetic Diversity, Polymorphism, and Drug Resistance Mutations in HIV-1 CRF02_AG and nonCRF02_AG Infected Patients in Yaoundé, Cameroon. Scientific Reports, 14136.

[29] Plantier, J.C., Leoz, M., Dickerson, J.E., De Oliveira, F., Cordonnier, F., Lemée, V., Damond, F., Roberson, D.L. and Simon, F. (2009) A New Human Immunodeficiency Virus Derived from Gorillas. Nature Medicine, 15, 871-872. https://doi.org/10.1038/nm.2016

[30] World Health Organisation (2017) HIV Drug Resistance Report 2017. World Health Organiation, Geneva. Consulted on 20/10/2019 at 7 am.

[31] Fokam, J., Salpini, R., Santoro, M.M., Cento, V., Perno, C.F., Colozzi, V.M.D., Peter Martins, M.D., Fokunang, N., Ndiang, T., Suzie, M., Nanfack Aubin, J., Takou, K., Désiré, A. and Cappelli, G. (2011) Drug resistance among grug-naïve and first-line antiretroviral treatment-failing children in Cameroon. The Pediatric Infection Disease Journal, 30, 1062-1068. https://doi.org/10.1097/INF.0b013e31822db54c

[32] Lihana, R.W., Ssemwanga, D., Abimiku, A. and Ndembi, N. (2012) Update on HIV-1 Diversity in Africa: A Decade in Review. AIDS Reviews, 14, 83-100.

[33] Billong, S.C., Fokam, J., Aghokeng, A.F., Milenge, P., Kembou, E., Abessouguie, I., Meva'a-Onglene, F.B., Zoung-Kanyi, A.C., Colizzi, V., Mpoudi, E.N., Elat Jean-Bosco, N. and Shiro, K.S. (2013) Population-Based Monitoring of Emerging HIV-1 Drug 
Resistance on Antiretroviral Therapy and Associated Factors in a Sentinel Site in Cameroon: Low Levels of Resistance but Poor Programmatic Performance. PLoS ONE, 8, e72680. https://doi.org/10.1371/journal.pone.0072680

[34] Avelin, F.A., Charles, K., Martine, P., Eitel, M.N. and Eric, D. (2013) Successful Integrase Inhibitor-Based Highly Active Antiretroviral Therapy for a MultidrugClass-Resistant HIV Type 1 Group O-Infected Patient in Cameroon. AIDS Research and Human Retroviruses, 29, 1-3. https://doi.org/10.1089/aid.2012.0196

[35] Emilande, G. (2016) Etude des résistances du VIH-1 au traitement antirétroviral et amélioration du suivi virologique des patients vivant avec le VIH dans les pays du Sud. Médecine humaine et pathologie. Université Montpellier, Français. NNT: 2016MONTT044. Tel-01647140.

[36] Florian, L., Caroline, V., Sabrina, E.D., Jeanne, S., Laurent, M. and Augustin, M.O., Arnaud D, Vanina B, Christelle B, Martine P, Jean-Paul G, Eric D and François R. (2012) Virological Failure Rates and HIV-1 Drug Resistance Patterns in Patients on First-Line Antiretroviral Treatment in Semirural and Rural Gabon. Journal of the International AIDS Society, 15, 17985. https://doi.org/10.7448/IAS.15.2.17985

[37] Abdelaye, K. (2018) Prise en charge de l'infection par HIV-1 dans les pays en développement: aspects diagnostiques et évaluation immuno-virologique de l'efficacité thérapeutique dans le sang et les compartiments muqueux. Médecine humaine et pathologie. Université de Lyon, Français. NNT: 2018LYSES061. Tel-02172061.

[38] Cyrille, F.D., Nathan, D.W., Nicole, V., Ubald, T., Celine, M., Matthew Le, B., Brian, L.P., Joseph, F., Wilfred, F.M., Alogos, B., Anne, W.R., Karen, S., Eitel, M.N., Michael, P.G. and Martine, P. (2013) HIV Type 1 pol Gene Diversity and Genotypic Antiretroviral Drug Resistance Mutations in Malabo, Equatorial Guinea. AIDS Research and Human Retroviruses, 29, 1085-1091.

[39] Patricia, A., Carolina, F.M., Luis, P., Leticia, M., Jacinta, O., Pedro, A., Antonio, V., Pablo, R., Agustın, B., Jose, T.R. and Holguin, A. (2016) HIV-1 Variants and Drug Resistance in Pregnant Women from Bata (Equatorial Guinea): 2012-2013. PLoS $O N E, 11$, e0165333. https://doi.org/10.1371/journal.pone.0165333

[40] Valerie, M., Valerie, J., Benjamin, S., Josianne, L., Pulcherie, P., Valentin, F., Philippe, G., Luc, S.H., Charles, G., Eugène, S., Ahidjo, A. and Hervé, F. (2013) Increasing HIV Type 1 Polymorphic Diversity But No Resistance to Antiretroviral Drugs in Untreated Patients from Central African Republic: A 2005 Study. AIDS Research and Human Retroviruses, 25, 1036-1044.

[41] Helene, P., Charlotte, C., Pascal, M., Marius, D., Mathieu, M., Sandrine, M., Jean De, D.L., Gerard, G., Bruno, A. and Laurent, B. (2012) Virological Response and Resistance Profiles after 24 Months of First-Line Antiretroviral Treatment in Adults Living in Bangui, Central African Republic. AIDS Research and Human Retroviruses, 28, 315-323. https://doi.org/10.1089/aid.2011.0127

[42] Kamangu, N.E., Chatte, A., Susin, F., Boreux, R., Kalala, R.L., Mvumbi, G.L., De Mol, P., Vaira, D. and Hayette, M.-P. (2015) Genetic Diversity and Antiretroviral Drug Resistance among Drug-Naïve HIV Type 1 Infected Patients Attending Clinics in Kinshasa, Democratic Republic of Congo. Journal of HIV and AIDS, 1, 1-6. https://doi.org/10.16966/2380-5536.101

[43] Kamangu, N.E., Bulanda, I.B., Bongenia, I.B., Botomito, T.H., Mvumbi, L.G., De Mol, P., Vaira, D., Hayette, M.P. and Kalala, L.R. (2015) Profil Epidémiologique Moléculaire de l'infection à VIH Type $1 \mathrm{chez}$ les patients naïfs de traitement à Kinshasa. Annales Africaines de Médecine, 8, 2136-2141. https://doi.org/10.4236/oalib.1101564 
[44] Kamangu, N.E., Bongenya, I.B., Bulanda, I.B., Kalume, A.A., Mabanza, M.P., Mvumbi, L.G., Hayette, M.P., Vaira, D. and Kalala, L.R. (2018) Molecular and Virological Profile of Professional Sex Workers (PSW) and Their Partners at the Beginning of ARV Treatment at IST Matonge in Kinshasa. Journal of HIV \& Retro Virus, 4, 10. https://doi.org/10.21767/2471-9676.100042

[45] Kamangu, N.E. (2016) Human Immunodeficiency Virus Type 1 and Type 2 CoInfection Rate in Kinshasa's Patients. Mathews Journal of HIVI AIDS, 1, 1-3.

[46] Bianca, B., Francesco, S., Laura, S., Franc, A.M.M., Renata, B., Patrizia, C., Anna, C., Maurizio, Z., Giancarlo, I., Claudio, V. and Francesca, B. (2015) Prevalence of HIV-1 Subtypes and Drug Resistance Associated Mutations in HIV-1 Positive Treatment-Naïve Pregnant Women in Pointe Noire, Republic of the Congo (KentoMwana Project). AIDS Research and Human Retroviruses, 31, 1-10.

https://doi.org/10.1089/aid.2015.0105

[47] Vidal, N., Koyalta, D., Richard, V., Lechiche, C., Ndinaromtan, T., Djimasngar, A., Delaporte, E. and Peeters, M. (2003) High Genetic Diversity of HIV-1 Strains in Chad, West Central Africa. JAIDS Journal of Acquired Immune Deficiency Syndromes, 33, 239-246. https://doi.org/10.1097/00126334-200306010-00020

[48] Adawaye, C., Fokam, J., Kamangu, E.N., Mahamat, A.H., Moussa, C.A., Susin, F., Mahamat, M.A., Hig-Zounet, T.B., Tidjani, A., Vaira, D. and Moutschen, M. (2017) Virological Response, HIV-1 Drug Resistance Mutations and Genetic Diversity among Patients on First-Line Antiretroviral Therapy in N'Djamena, Chad: Findings from a Cross-Sectional Study. Open Access, 10, 589. https://doi.org/10.1186/s13104-017-2893-1

[49] Raphael, W.L., Deogratius, S., Alash'le, A. and Nicaise, N. (2012) Update on HIV-1 Diversity in Africa: A Decade in Review. AIDS Reviews, 14, 83-100. 